A randomised observational study of individualised variations in the start position of the Closed-Kinetic Chain Upper Extremity Stability Test

\author{
Andrew Callaway, Joshua Peck, Shelley Ellis, Jonathan Williams \\ Department of Rehabilitation and Sport Science \\ Bournemouth University
}

Objectives: To assess the reliability, precision and differences between scores produced using the standard 36" start position and 3 modified start positions of the Closed Kinetic Chain Upper Extremity Stability Test (CKCUEST), towards normalization to the individual.

Design: RCT of 4 conditions.

Setting: Clinical.

Participants: Thirty-four asymptomatic individuals.

Main outcome measures: Using an RCT method, variations in CKCUEST starting hand position were tested using hand spacing at standard 36”, 50\% height, bi-acromial distance, and bi-acromial distance with reach to 36”. The average number of touches over $3 \mathrm{x} 15 \mathrm{~s}$ maximal efforts were averaged. The intra-variation reliability, minimum detectable change (MDC) and differences to the standard 36" start position were tested.

Results: The most reliable variation was the 50\% height (ICC: 0.93 ) and with the smallest MDC (14\%). 36" results were second-most reliable (ICC: 0.90), with a low MDC (19\%). Significant differences were found between bi-acromial and 50\% height to the 36 ” standard setup.

Conclusions: A setup position where the hand separation is $50 \%$ of the individual's height offers excellent repeated measures reliability and the smallest MDC, suggesting it is the most sensitive to change and is a recommendation to clinicians. Conversion calculations between start variations are presented.

Keywords: isokinetic; shoulder stability; CKCUEST; closed-kinetic 


\section{A randomised observational study of individualised variations in the start position of the Closed-Kinetic Chain Upper Extremity Stability Test}

Objectives: To assess the reliability, sensitivity and differences between scores produced using the standard 36" start position and 3 modified start positions of the Closed Kinetic Chain Upper Extremity Stability Test (CKCUEST), towards normalization to the individual.

Design: RCT of 4 conditions.

Setting: Clinical.

Participants: Thirty-four asymptomatic individuals.

Main outcome measures: Using an RCT method, variations in CKCUEST starting hand position were tested using hand spacing at standard 36”, 50\% height, bi-acromial distance, and bi-acromial distance with reach to 36". The average number of touches over $3 \mathrm{x} 15 \mathrm{~s}$ maximal efforts were averaged. The intra-variation reliability, minimum detectable change (MDC) and differences to the standard 36” start position were tested.

Results: The most reliable variation was the 50\% height (ICC: 0.93) and with the smallest MDC (14\%). 36" results were second-most reliable (ICC: 0.90), with a low MDC (19\%). Significant differences were found between bi-acromial and 50\% height to the 36 ” standard setup.

Conclusions: A setup position where the hand separation is $50 \%$ of the individual's height offers excellent repeated measures reliability and the smallest MDC, suggesting it is the most sensitive to change and is a recommendation to clinicians. Conversion calculations between start variations are presented.

Keywords: isokinetic; shoulder stability; CKUEST; closed-kinetic 


\section{Introduction}

The Closed-Kinetic Chain Upper Extremity Stability Test (CKCUEST) as originally proposed by Goldbeck and Davis (2000) is a quick and simple test believed to assess the neuromuscular control of the upper limb during a closed-kinetic chain task. Since its proposal, the CKCUEST is one of the most commonly used and researched tests of physical performance in the upper limb (Tarara et al., 2016). The test involved starting in a press-up position with hands 36” $(91.44 \mathrm{~cm})$ apart, and during three repeated maximal 15 second trials, one hand is lifted to touch the other hand.

Extensive previous study of the CKCUEST has established a variety of results for the test across a range of populations and conditions (Table 1). Furthermore, Tucci et al., (2014) demonstrated that the CKCUEST had discriminatory validity between differing clinical populations. In addition, the test has also been extensively explored in terms of repeated measures reliability (Table 1), with good to excellent reliability metrics. 
Table 1. Literature using CKCUEST with average results and information about the participants. ICC; intraclass correlation coefficient, NR; not reported.

\begin{tabular}{|c|c|c|c|}
\hline Author & Population (sample) Location & $\begin{array}{l}\text { Average of } \\
\text { touches }\end{array}$ & ICC \\
\hline $\begin{array}{l}\text { Goldbeck and } \\
\text { Davis (2000) }\end{array}$ & Male university students (24) USA & 27.8 & 0.92 \\
\hline $\begin{array}{l}\text { Roush et al. } \\
\text { (2007) }\end{array}$ & Male university Baseball players (77) USA & 30.4 & NR \\
\hline \multirow[t]{2}{*}{$\begin{array}{l}\text { Westerick et al. } \\
\text { (2012) }\end{array}$} & Male (24) USA & 18.8 & NR \\
\hline & Female (6) USA & 15.9 & NR \\
\hline $\begin{array}{l}\text { Pontillo et al. } \\
\text { (2014) }\end{array}$ & $\begin{array}{l}\text { Male university American football players (26) } \\
\text { USA }\end{array}$ & 22.5 & NR \\
\hline \multirow[t]{6}{*}{$\begin{array}{l}\text { Tucci et al. } \\
\text { (2014) }\end{array}$} & Sedentary Male (20) Brazil & 25.49 & $\begin{array}{c}0.84- \\
0.90\end{array}$ \\
\hline & Active Male (20) Brazil & 26.53 & \\
\hline & $\begin{array}{l}\text { Male Subacromial Impingement Syndrome } \\
\text { (13) Brazil }\end{array}$ & 10.96 & \\
\hline & Active Female (20) Brazil & 29.97 & \\
\hline & Sedentary Female (20) Brazil & 25.96 & \\
\hline & $\begin{array}{l}\text { Female Subacromial Impingement Syndrome } \\
\text { (15) Brazil }\end{array}$ & 12.97 & \\
\hline \multirow[t]{2}{*}{$\begin{array}{l}\text { Sciascia and Uhl } \\
\text { (2015) }\end{array}$} & Asymptomatic (9 Male, 10 Female) USA & 22 & 0.85 \\
\hline & Symptomatic (9 Male, 9 Female) USA & 22 & 0.86 \\
\hline $\begin{array}{l}\text { Lee and Kim } \\
\text { (2015) }\end{array}$ & Adults (20 male, 20 female) Korea & 13.2 & 0.97 \\
\hline \multirow[t]{2}{*}{$\begin{array}{l}\text { de Oliveira et al. } \\
\text { (2017) }\end{array}$} & Healthy adults (11 males, 14 females) Brazil & 25.6 & 0.96 \\
\hline & Retest & 28 & \\
\hline Bernardo (2018) & $\begin{array}{l}\text { Recreational university athletes (11 male, } 1 \\
\text { female) USA }\end{array}$ & 23.7 & NR \\
\hline
\end{tabular}


Despite valid and reliable results within some populations, Goldbeck and Davies (2000) do acknowledge some limitations to their proposed test which is reiterated by Roush et al. (2007). Firstly, it is well understood that participants must be willing and able to accept their body weight with the potential high load on the wrists, elbow and shoulder joints. Secondly, sufficient core strength and stability is required to successfully complete the assessment. However, one aspect which has been somewhat overlooked is the modification of the test for the individual anthropometrics. A potential issue that is shared by Tucci et al. (2014) and Tucci et al. (2017). Within the initial conception of the CKCUEST (Goldbeck and Davies, 2000), the hand placement 36” $(91.44 \mathrm{~cm})$ apart as standard is not justified. It could be assumed that 36" was chosen as half of 6ft which was perhaps the average height of the population used, but not reported (Male athletes). Six foot $(185 \mathrm{~cm})$ is around the 95th percentile of mens' height according to the generalised population statistics collated by Pheasant, \& Haslegrave (2018), suggesting that this value would not be representative across male and female populations.

It has been shown that different hand placement during push-ups alters muscle activity (Cogley et al., 2005) and therefore it is likely that to reach the 36" hand placement individuals with 'narrow' shoulders will use different muscles to those with 'broad' shoulders. Pheasant and Haslegrave (2018) produced anthropometric data for male and female populations covering 5th, 50th and 95th percentile. If we assume that in the press-up start position the body creates an isosceles trapezoid, then using these data for bi-acromial distance and arm length (arm length was calculated as: [forearm to finger tips minus hand 
length]+[upper arm]), the theoretical joint angle at the shoulder $(\theta)$ can be calculated (Figure 1).

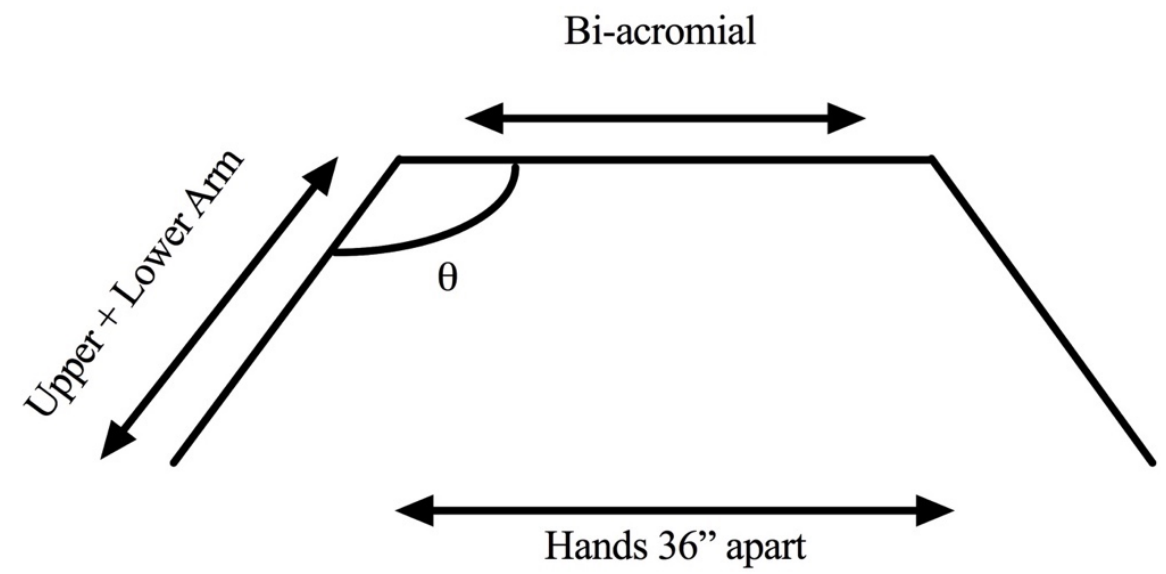

Figure 1 Representation of a participant in the start position for CKCUEST

Using this model, estimates of shoulder angle for different start conditions were plotted against the percentile of the population (Figure 2). Different start positions were modelled and plotted; 36" in line with the original test description, 50\% height demonstrates the effect of normalisation to the individuals' anthropometrics and $150 \%$ bi-acromial distance as this was trialled by Tucci et al. (2017), and hands below the shoulders producing $90^{\circ}$.

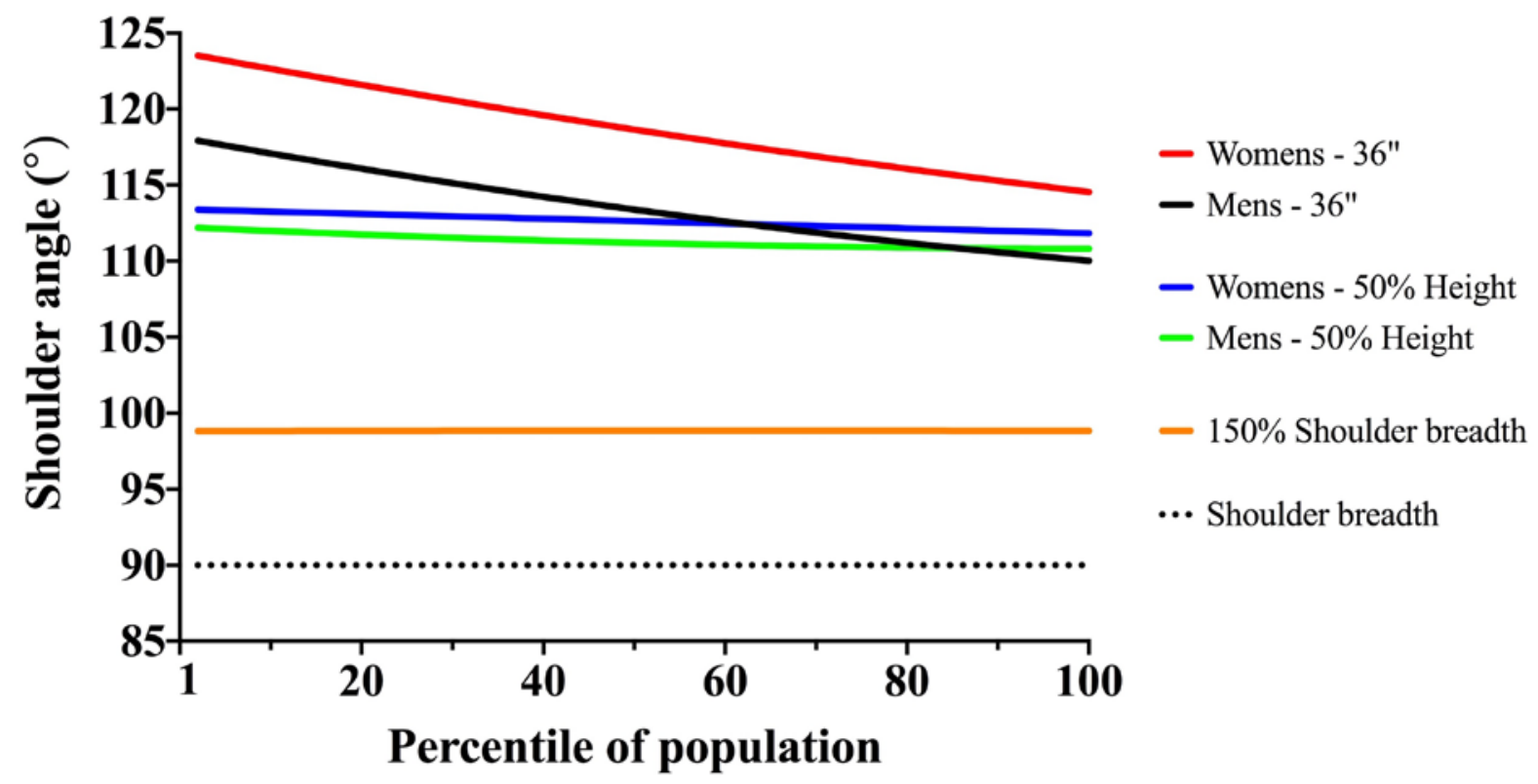




\section{Figure 2 Calculation of shoulder angle in different start up positions}

For men and women using the 36 ” hand position, there is an inconsistency across the range of heights, meaning taller individuals are likely advantaged over those who are shorter. There is also an inconsistency between men and women, with women experiencing increased angles when compared to men. Using $50 \%$ of a participant's height, there is still a difference between men and women, but much less of a difference than seen with the 36” position, and the angles are similar to the originally proposed $36^{\prime \prime}$ hand position around $111^{\circ}( \pm 1)$ and $112^{\circ}$ $( \pm 1)$, respectively. $150 \%$ bi-acromial distance produces an angle of $99^{\circ}$, which is consistent between men and women within a tenth of a degree, and hands directly underneath the shoulders produces a consistent $90^{\circ}$ shoulder angle.

The lack of normalisation to the individual is likely to result in differences in angle and muscle activity and thus performance of the CKCUEST. Previous authors have explored modified hand placements. Tucci et al (2017) investigated the original 36”, bi-acromial distance and $150 \%$ of bi-acromial distance, however the aim of their study was to explore the biomechanics and not the outcome or reliability of the proposed modifications. Degot et al., (2019) tested one half of the arm span (C7 spinous process to top of the middle finger) and despite demonstrating good to excellent reliability no attempts were made to compare the modified score to the original test, therefore it is not clear whether the modification resulted in any difference in score. 
Therefore, the aim of this paper was to assess the 1) reliability, 2) sensitivity, and 3) differences between different hand start position conditions for the CKCUEST.

\section{Methodology}

\section{$\underline{\text { Testing procedure }}$}

For the CKCUEST participants adopted a push-up position with hands 36” $(91.44 \mathrm{~cm})$ apart, perpendicular to the floor. Lines added to the floor ensured consistency and accuracy of placement for repeated and subsequent tests. Participants were required to lift one hand and touch the other hand, resulting in a shift in weight towards the static hand, with the objective of achieving as many touches as possible in $15 \mathrm{~s}$. Two examiners were used, one to count the touches, and one to control the timing. The process was repeated 3 times and a rest period of 45 seconds was given between repeats, equating to a minimum of 1:3 work:rest ratio (Goldbeck and Davies 2000; Tucci et al. 2014; Haff and Trilett 2015). A test (3 x 15 s) was done once a week. Over a 4-week testing period, the variations seen below were randomly selected for each participant each week.

\section{$\underline{\text { Test variations }}$}

1. The standard test using hand placement distance of 36” $(91.44 \mathrm{~cm})$, as described by Goldbeck and Davis (2000) (Figure 3).

2. Hand placement equivocal with shoulder breadth (bi-acromial) distance, and perform the test as described by Goldbeck and Davis (2000).

3. Hand placement starting at bi-acromial distance, and touch to 36” (Figure 4). 
4. Hand placement starting at $50 \%$ of the participants height, and perform the test as described by Goldbeck and Davis (2000).
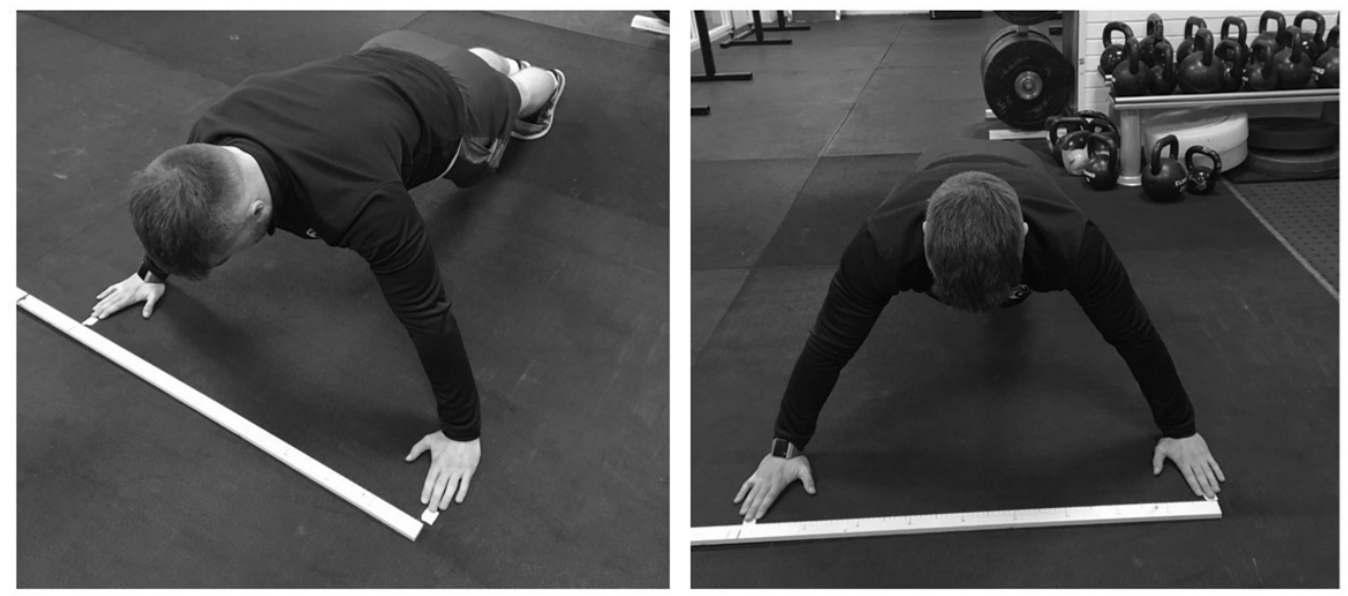

Figure 3 This is the distance of 36”, the same distance used by Goldbeck and Davis (2000)
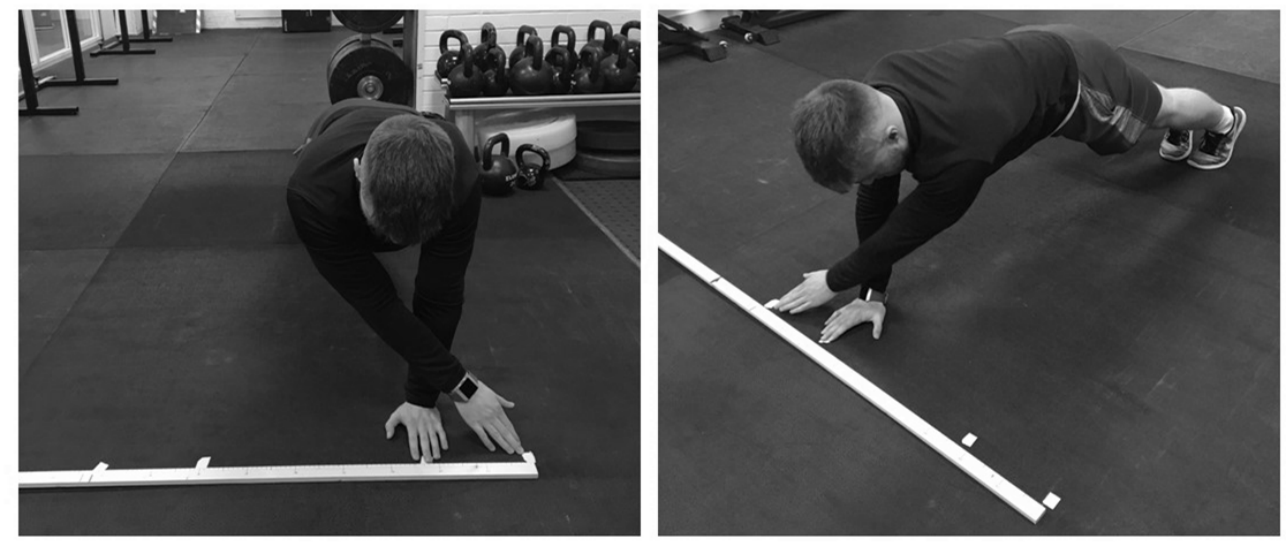

Figure 4 Third variation of testing, with hand placement starting at bi-acromial distance, then having to reach over the top of the hand to 36 ”

\section{$\underline{\text { Participants }}$}

Sample size calculations for one group with 4 repeated measures were calculated using G*Power 3.1 considering the following values: $\alpha=0.05 ; \beta=0.1$ (90\% power), correlation between repeated measures 0.5 , revealing a sample requirement of 30 . 
With institutional ethical approval, a total of 34 participants completed all four weeks of testing in each test variation, with average height of $177.61 \pm 8.6 \mathrm{~cm}$, weight $84.40 \pm 13.8 \mathrm{~kg}$ and shoulder breadth $42.45 \pm 4.65 \mathrm{~cm}$. All participants were male, to enable comparison to similar previous work. Participants were all injury free at the time of the testing period.

\section{Body measurements}

Stature (height in cm), weight (mass in kg) and shoulder breadth (bi-acromial) (distance in $\mathrm{cm})$ measurements were all measured following The International Society for the Advancement of Kinanthropometry (ISAK) guidelines (Stewart, Marfell-Jones, Olds \& de Ridder, 2011).

Stature was recorded using a standard laboratory stadiometer. The participant stood barefoot with their heels together and the heels, buttocks and upper back of the back touching the scale. The head was positioned in the Frankfort position (Orbitale in the same horizontal plane as the Tragion). With the head positioned, the measurer positions their thumbs posteriorly towards the ears so that when upward pressure is applied it transferred through the mastoid processes. The subject is instructed to take and hold a deep breath, and keeping the head in plane, the measurer applies upward pressure and takes the measurement.

Mass was recorded using a Seca weighing scales. The participant stood with their feet fully on the scales looking directly ahead.

A Cescorf large sliding caliper was used to measure the bi-acromial distance. The subject was in a relaxed standing position with the arms hanging by the sides. The distance was measured by standing behind the subject with the caliper branches at $30^{\circ}$ pointing upwards, the 
branches were brought inwards on the most lateral surface of the acromion process and pressure was applied to compress the underlying tissue but without moving the shoulders.

All measures were taken twice and were within ISAK margins of error (1\%), with the mean measurement taken forward to calculations.

\section{Protocol}

A test ( $3 \times 15$ s) was undertaken sub maximally for participants to understand the testing protocol and serve as a warm up. When the participant was ready to start the test the correct distance was established, the participant would get into a press-up position with their middle finger on the tape marked, their feet touching, and their body flat and parallel to the floor. The participant would then have $15 \mathrm{~s}$ to complete as many touches as possible. No verbal encouragement was given after the "go" command.

\section{$\underline{\text { Data analysis }}$}

The test outcome was converted into three performance metrics. Firstly, the mean number of touches across the three trials; secondly the mean number of touches normalised by participant height and finally, to a power score calculated by multiplying the mean touches by 68\% of the person's body weight, divided by 15 (Goldbeck and Davis 2000; de Oliveira 2017). These performance metrics were then subject to internal reliability assessment for each test variation using the intraclass correlation coefficient (ICC)(3,k) (McGraw \& Wong, 1996). In addition, the $95 \%$ confidence minimal detectable change (MDC) was calculated using the following formula (Eliasziw et al. 1994):

$$
\mathrm{MDC}_{95}=\text { standard error of measurement } \times 1.96 \times \sqrt{ } 2
$$


Using the one sample Kolmogorov-Smirnov test all data were normally distributed ( $\mathrm{p}>$ 0.05). Significant difference between the test variations were explored using a one-way ANOVA test within SPSS version 21, with post-hoc comparison using Bonferroni where appropriate. Significance testing was set to 0.05 .

\section{$\underline{\text { Results }}$}

\section{Reliability}

The ICC values suggest that all tests offer good to excellent reliability with values greater than 0.84 (Table 2). Regarding the metrics, the scores normalised to height seem to offer slightly greater levels of repeated measures reliability across the tests. Regarding the test variations, the test with hand placement equivocal to $50 \%$ height seems to offer greatest reliability regardless of metric. This finding is mirrored across the standard error of measurement (SEM) and minimum detectable change (MDC) with consistently the smallest SEM and MDC being demonstrated with hand placement equivocal to 50\% height. Little variation was observed for the three metrics. These figures demonstrate that a change in excess of $15 \%$ of the mean can be considered a true change, beyond the natural variance of repeated testing, with 95\% confidence, when the hand position matched 50\% height. 
Table 2 Reliability estimates across metrics and test variations

\begin{tabular}{|c|c|c|c|c|}
\hline Variation & & Mean touches & $\begin{array}{c}\text { Normalised to } \\
\text { height }\end{array}$ & Power score \\
\hline \multirow{6}{*}{$36 ”$} & Mean touches $( \pm S D)$ & $25.36( \pm 5.0)$ & $0.14( \pm 0.03)$ & $96.70( \pm 21.9)$ \\
\hline & \multirow{2}{*}{ ICC } & 0.90 & 0.91 & 0.89 \\
\hline & & $(0.73-0.96)$ & $(0.74-0.96)$ & $(0.81-0.94)$ \\
\hline & SEM & 1.72 & 0.009 & 7.74 \\
\hline & MDC & 4.76 & 0.026 & 21.44 \\
\hline & MDC as \% of mean & $19 \%$ & $18 \%$ & $22 \%$ \\
\hline \multirow{6}{*}{$\begin{array}{l}\text { Shoulder } \\
\text { breadth }\end{array}$} & Mean touches $( \pm S D)$ & $34.25( \pm 6.1)$ & $0.19( \pm 0.04)$ & $129.59( \pm 23.8)$ \\
\hline & \multirow{2}{*}{ ICC } & 0.84 & 0.87 & 0.86 \\
\hline & & $(0.71-0.92)$ & $(0.75-0.93)$ & $(0.75-0.93)$ \\
\hline & SEM & 2.85 & 0.015 & 10 \\
\hline & MDC & 7.78 & 0.043 & 27.72 \\
\hline & MDC as \% of mean & $23 \%$ & $22 \%$ & $21 \%$ \\
\hline \multirow{6}{*}{$\begin{array}{c}\text { Shoulder } \\
\text { breadth to } \\
36 ”\end{array}$} & Mean touches $( \pm S D)$ & $23.32( \pm 5.7)$ & $0.13( \pm 0.03)$ & $87.48( \pm 20.6)$ \\
\hline & \multirow{2}{*}{ ICC } & 0.89 & 0.91 & 0.89 \\
\hline & & $(0.81-0.94)$ & $(0.83-0.95)$ & $(0.81-0.94)$ \\
\hline & SEM & 2.06 & 0.011 & 7.48 \\
\hline & MDC & 5.72 & 0.03 & 20.72 \\
\hline & MDC as \% of mean & $25 \%$ & $23 \%$ & $24 \%$ \\
\hline \multirow{6}{*}{$\begin{array}{c}50 \% \\
\text { height }\end{array}$} & Mean touches $( \pm S D)$ & $29.13( \pm 5.3)$ & $0.17( \pm 0.03)$ & $110.29( \pm 21.5)$ \\
\hline & \multirow{2}{*}{ ICC } & 0.93 & 0.93 & 0.94 \\
\hline & & $(0.87-0.97)$ & $(0.87-0.96)$ & $(0.88-0.97)$ \\
\hline & SEM & 1.49 & 0.009 & 5.54 \\
\hline & MDC & 4.14 & 0.024 & 15.35 \\
\hline & MDC as \% of mean & $14 \%$ & $15 \%$ & $14 \%$ \\
\hline
\end{tabular}




\section{Differences}

Comparing the mean touch scores, there were significant differences between the conditions $[\mathrm{F}(3,132)=25.177, \mathrm{p}<0.001]$. Post-hoc Bonferroni tests (Figure 5) showed significant differences $(\mathrm{p}<0.05)$ between conditions, 36” and shoulder breadth, 36” and 50\% height, shoulder breadth and shoulder breath to 36", shoulder breadth and 50\% height, shoulder breath to 36 ” and 50\% height.

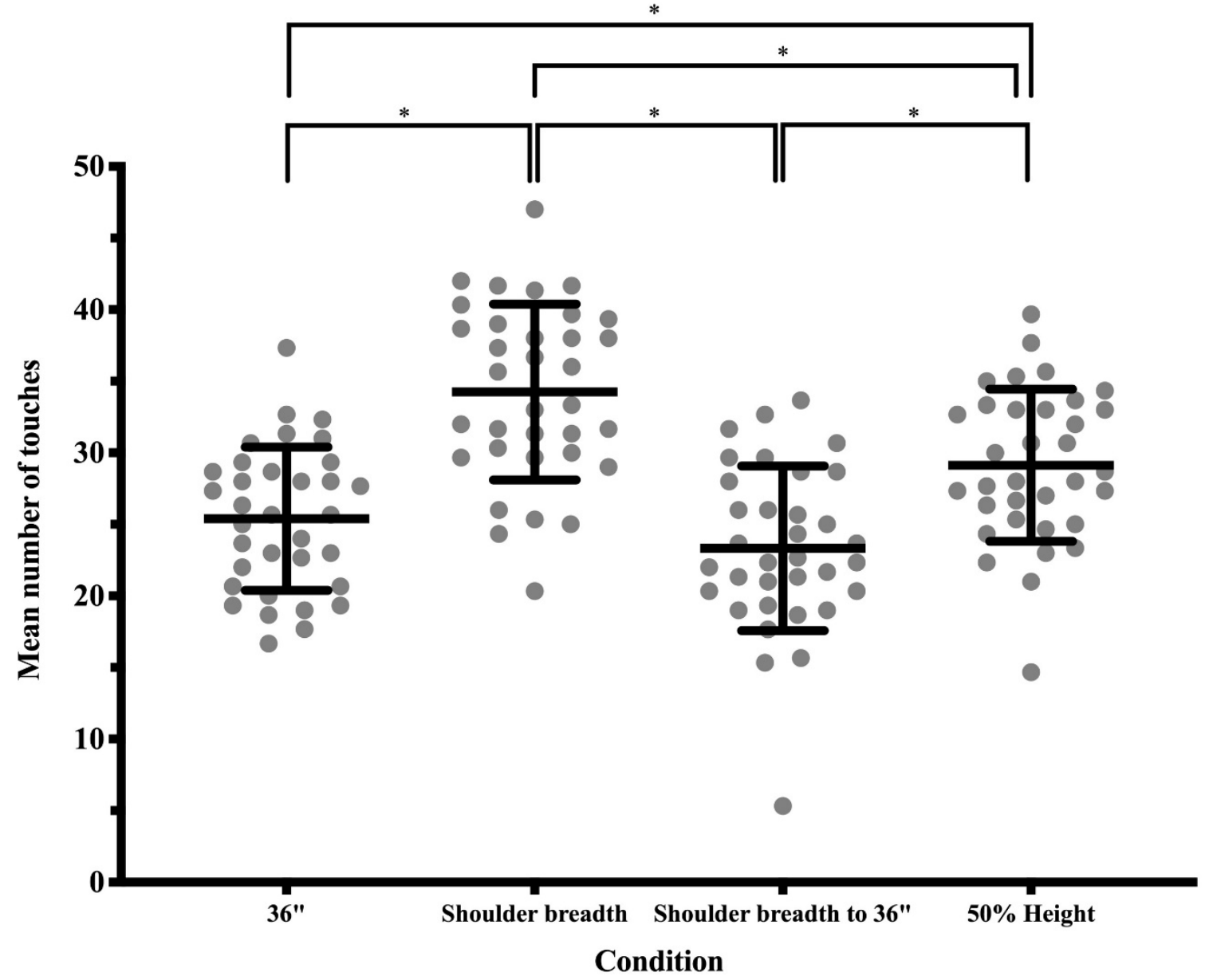

Figure 5 Mean (+/-SD) number of touches between conditions 
Comparing the mean touch normalised by height scores, there were significant differences between the conditions $[\mathrm{F}(3,132)=23.333, \mathrm{p}<0.001]$. Post-hoc Bonferroni tests (Figure 6) showed the same differences as with the mean touches.

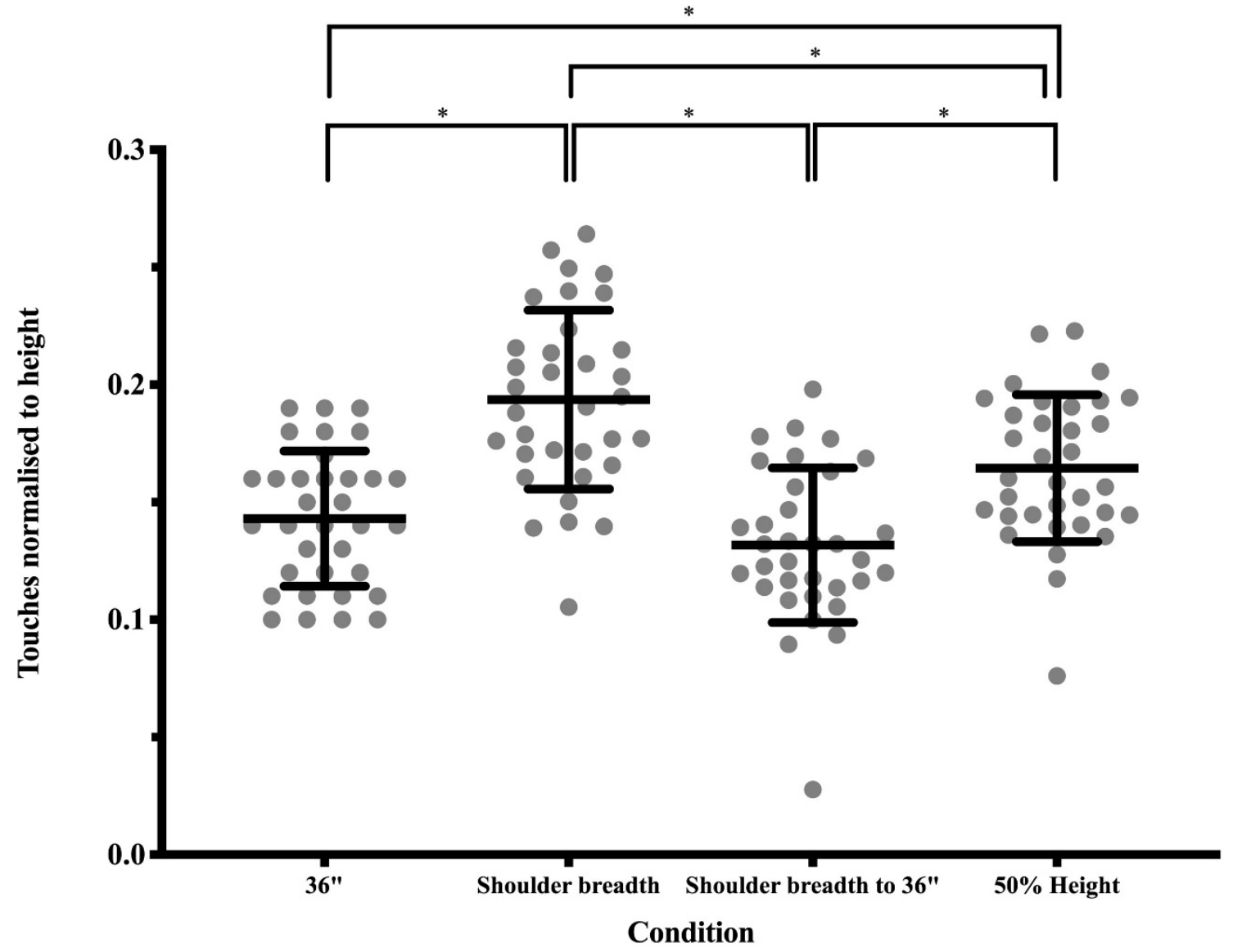

Figure 6 Mean (+/-SD) number of touches, normalised to height, between conditions

Comparing the power scores between conditions showed significant differences $[F(3,132)=$ 23.555, $\mathrm{p}<0.001$ ]. Post-hoc Bonferroni tests (Figure 7) showed the same significant differences $(\mathrm{p}<0.05)$ between conditions, with the exception of no significant difference between 36 ” and 50\% height. 


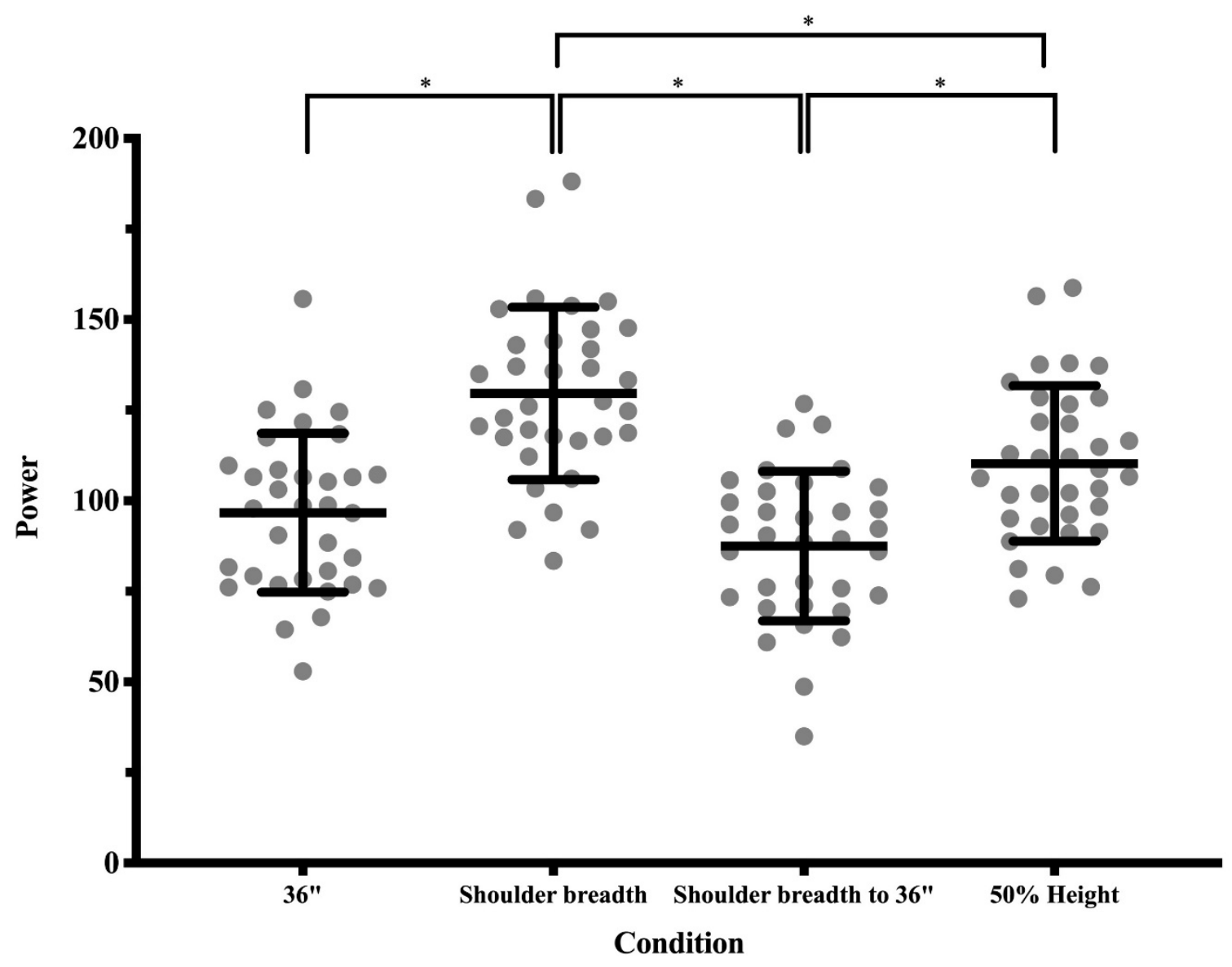

Figure 7 Mean (+/-SD) power between conditions

\section{Discussion}

The aim of this study was to test three variant start positions on the CKUEST compared to the original 36 " to identify reliability and any differences. Overall, the results show that internal reliability is not affected by changes in the positions of the setup position with very high reliability (ICC: 0.84-0.94) for all variations. This finding agrees with all previous literature which demonstrates excellent ICC values for the CKUEST or its slight variation (Table 1). This demonstrates that minor manipulation to the starting position has little effect on the consistency of the test as measured by ICC. Therefore, from the clinician's perspective, any start position that remains consistent offers repeatable testing. This also 
reiterates Gorman et al. (2012) notion that in this position, athletes are in a stable base of support and not necessarily being challenged. However, the additional metrics demonstrate different sensitivity to change. The MDC values suggest that initial start position set to $50 \%$ of the individual's height offers the smallest MDC values regardless of the metric being measured. For this start position a clinician can be 95\% confident that a change greater than $15 \%$ of the initial test score is indicative of true change, rather than natural variation in performance of the test. Therefore, this starting position is most sensitive to determining change, for example due to intervention.

Despite relative minor test manipulations there was a significant difference between them. There was no real difference between the calculations methods of 'normalised to height' and 'mean touches', which suggests that they could be more discriminatory than the use of power scores. Previous studies have investigated different variations in start positions but not compared to the original 36" to identify any differences. Tucci et al (2017) investigated the original 36”, bi-acromial distance and $150 \%$ of bi-acromial distance, however the aim of the study was to explore the biomechanics and not the outcome or reliability of the proposed modifications. Degot et al., (2019) tested arm span as setup position distance demonstrating good to excellent reliability, but with no attempts to compare the modified score to the original test.

In the current work, the first variation was shoulder breadth (bi-acromial) which offers a consistent $90^{\circ}$ shoulder angle regardless of the participants population percentile. The results show a significant increase in hand touches which would be expected with the hands closer together, with less movement of the shoulder joint to move the hands to one another. Tucci et 
al. (2017) conducted the first kinetic and kinematic analysis of various positions, and reported that this position was most preferred when compared to normal (36”) and 150\% bi-acromial.

The second variation was bi-acromial with the subject reaching past the other hand to the 36" mark. This variation had the same start position ( $90^{\circ}$ shoulder angle), however the reach to 36” started to incorporate some elements which mirror the Upper Quarter Y Balance Test (UQYBT) with a reach past the supporting arm. Unlike the UQYBT, a maximal effort of touches within 15 seconds showed that there were significantly fewer touches made compared to the standard 36” touch, shoulder breadth, and 50\% height variations. This would be expected with the navigation required to move past the supporting arm, but there is no extra distance increase. In the standard test, the feet act as a pivot allowing rotation of the trunk, requiring core strength, which has been a criticism of the standard test so far (Roush et al. 2007). Additionally, having the support arm directly under the shoulder and reaching past puts a greater load on the supporting shoulder joint which could be challenging for individuals with a painful shoulder, a similar criticism could be made of the UQYBT.

The third variation utilised a start position of 50\% height, which produced an approximate shoulder angle of $112^{\circ}$ for each gender (Figure 2). Standardising this to a known measure of $50 \%$ height has now been shown to be reliable. This position is very similar to the recent adaptation by Degot et al. (2019) using half arm span, where full arm span is close to a person's height measure. The participants in the current study completed a slightly higher mean number at 25 touches, compared to a mean from multiple sessions and trails of 22-23 touches reported by Degot et al. (2019). This variation in the testing shows that even for males of similar ages, heights there are large variations between participants. 
Despite the results appearing very similar, there is a significant difference in the mean number of touches between the 36” and 50\% height setup positions. This is a surprising result, with a theoretical average difference in shoulder angle, between 36 ” and 50\% height, per participant within this study of $1.31^{\circ}\left( \pm 2.01^{\circ}\right)$. Degot et al.'s (2019) study was to assess reliability of a modified procedure using a start position of half arm span. Whilst not the purpose of their study, they did not compare this to the original 36” position, given the results of the current work suggesting that small variations in start position can have significant changes in the mean number of touches, other modifications to the start potion should be considered to accommodate individuals' anthropomorphic variations. These findings reiterate the need for standardisation of the test across the population but could also draw attention to the need for precision in the setup positions where a small variation in starting positions could affect the test results, particularly where a clinician is using these results in a withinsubject setting.

Clinically, the CKCUES Test is used, therefore based on the finding of this study a setup position where the hand separation matched $50 \%$ of the individual's height offered excellent repeated measures reliability and the smallest MDC, suggesting it is the most sensitive to change. Conceptually it enables relative standardisation with individual normalisation thus considering anthropometric differences. Moreover, it has been demonstrated for the first time that such a setup position results in a different number of touches and therefore affects the outcome. Consequently, it is our recommendation that clinicians use the hand separation distance equivocal to $50 \%$ height. 
To aid clinicians, and researchers, with a transition from the original 36” variation to the other variations shown in this paper for historical data conversion or interest, this data can be calculated using the following linear regression equations $(\mathrm{p}<0.05)$. These may require future refinement to be used generically to include other factors such as age, height and gender.

To convert a variation to the standard 36” test results, these can be used: 


$$
\begin{aligned}
& 36 ” \text { score }=7.184+0.532(\text { Shoulder breath score }) \\
& 36 ” \text { score }=15.003+0.445(\text { Shoulder breath to } 36 ” \text { score }) \\
& 36 ” \text { score }=4.877+0.704(50 \% \text { height score })
\end{aligned}
$$

To convert from the standard 36" setup to other variations, use these:

$$
\begin{aligned}
& \text { Shoulder breadth score }=13.869+0.802(36 ” \text { score }) \\
& \text { Shoulder breath to } 36 \text { ” score }=8.354+0.59(36 \text { ” score }) \\
& 50 \% \text { height score }=8.914+0.796(36 \text { " score })
\end{aligned}
$$

\section{Limitations and future work}

The current study tested variations between different variations in start position for the CKCUES Test. The limitation of this work is that population contained all healthy male subjects. Future work needs to firstly investigate injured and symptomatic participants across the range of ages, heights, and gender in particular, to ensure that the reliability and MCD metrics hold true. Secondly, the validation of the test in different start positions should be examined. 


\section{$\underline{\text { References }}$}

Bernardo, J., 2018. Comparison of Isokinetic testing to upper extremity closed kinetic chain testing in recreational college athletes. Health and science student work. 13, p.1-39.

Cogley, RM., Archambault, TA., Fibeger, JF., Koverman, MM., Youdas, JW., Hooman, JH. 2005. Comaprison of muscle activation using various hand positions during the push up exercise. The journal of strength and conditioning research. 19, p.628-633.

Degot, M., Blache, Y., Vigne, G., Jure, D., Borel, F., Neyton, L., Rogowski, I. 2019. Intrarater reliability and agreement of a modified closed kinetic chain upper extremity stability test. Physical therapy in sport. 38, p.44-48.

Goldbeck, T. and Davies, G., 2000. Test-retest reliability of the closed kinetic chain upper extremity stability test: a clinical field test. Journal of sport rehabilitation. 9(1), p.35-45.

Gorman, P.P., Butler, R.J., Plisky, P.J. and Kiesel, K.B., 2012. Upper Quarter Y Balance Test: reliability and performance comparison between genders in active adults. The journal of strength \& conditioning research, 26(11), p.3043-3048. 
Haff, G. and Triplett, T., 2015. Essentials of strength training and conditioning. Fourth edition. United states. Human Kinetics.

Lee, D. and Kim, L., 2015. Reliability and validity of the closed kinetic chain upper extremity stability test. Journal of physical therapy science. 27, p.1071-1073.

McGraw, K. O., Wong, S. P., 1996. Forming Inferences About Some Intraclass Correlation Coefficients. Psychological methods, 1(1), p. 30-46

de Oliveira, V., Pitangui, A., Nascimento, V., da Silva, H., dos Passos, M. and Araújo., 2017. Test-retest reliability of the closed kinetic chain upper extremity stability test (CKCUEST) in adolescents. International journal of sport physical therapy. 12(1), p.125-132.

Pheasant, S. and Haslegrave, C.M., 2018. Bodyspace: Anthropometry, ergonomics and the design of work. CRC Press.

Pontillo, M., Spinelli, B. and Sennett, B., 2014. Prediction of in-season shoulder injury from preseason testing in division 1 collegiate football players. Sport health. 6(6), p.497-503. 
Roush, J., Kitamura, J. and Waits, M., 2007. Reference values for the closed kinetic chain upper extremity stability test (CKCUEST) for collegiate baseball players. North American journal of sports physical therapy, 2(3), p.159-163.

Sciascia, A., \& Uhl, T. (2015). Reliability of strength and performance testing measures and their ability to differentiate persons with and without shoulder symptoms. International journal of sports physical therapy. 10(5), p.655.

Stewart, A., Marfell-Jones, M., Olds, T., and de Ridder, H., 2011. International standards for anthropometric assessment. Australia, ISAK.

Tarara, D.T., Fogaca, L.K., Taylor, J.B. and Hegedus, E.J., 2016. Clinician-friendly physical performance tests in athletes part 3: a systematic review of measurement properties and correlations to injury for tests in the upper extremity. British journal of sports medicine. 50(9), p.545-551.

Tucci, H., Felicia, L., McQuade, K., Bevilaqua-Grossi, D., Camarini, P. and de Oliveira, A., 2017. Biomechanical analysis of the closed kinetic chain upper extremity stability test. Journal of sport rehabilitation. 26, p.42-50. 
Tucci, H., Martins, J., De Carvalho Sposito, G., Camarini, P. and de Oliveira, A., 2014. Closed kinetic chain upper extremity stability test (CKCUES test): a reliability study in persons with and without shoulder impingement syndrome. BioMed central musculoskeletal disorders. 15(1), p.1471-2474

Westrick, R.B., Miller, J.M., Carow, S.D. and Gerber, J.P., 2012. Exploration of the ybalance test for assessment of upper quarter closed kinetic chain performance. International journal of sports physical therapy, 7(2), p.139. 